\title{
Effects of early vaccination with Improvac (R) on the development and function of reproductive organs of male pigs
}

\author{
Stig Einarsson, Carl Brunius, Margareta Wallgren, Kerstin Lundstrom, Kristina Andersson, \\ Galia Zamaratskaia and Heriberto Rodriguez-Martinez
}

\section{Linköping University Post Print}

N.B.: When citing this work, cite the original article.

Original Publication:

Stig Einarsson, Carl Brunius, Margareta Wallgren, Kerstin Lundstrom, Kristina Andersson, Galia Zamaratskaia and Heriberto Rodriguez-Martinez, Effects of early vaccination with Improvac (R) on the development and function of reproductive organs of male pigs, 2011, Animal Reproduction Science, (127), 1-2, 50-55.

http://dx.doi.org/10.1016/j.anireprosci.2011.06.006

Copyright: Elsevier Masson http://www.elsevier-masson.fr/

Postprint available at: Linköping University Electronic Press http://urn.kb.se/resolve?urn=urn:nbn:se:liu:diva-72146 
1 Effects of early vaccination with Improvac ${ }^{\circledR}$ on the development and function of

2 reproductive organs of male pigs

3

4 Stig Einarsson ${ }^{\mathrm{a}}$, Carl Brunius ${ }^{\mathrm{b}}$, Margareta Wallgren ${ }^{\mathrm{a}, \mathrm{c}}$, Kerstin Lundström ${ }^{\mathrm{b}}$, Kristina

5 Andersson $^{\mathrm{d}}$, Galia Zamaratskaia ${ }^{\mathrm{b}}$, Heriberto Rodriguez-Martinez ${ }^{\mathrm{e}}$

6

$7 \quad{ }^{a}$ Department of Clinical Sciences, Division of Reproduction, Swedish University of

8 Agricultural Sciences (SLU), Uppsala SE-750 07 Sweden, ${ }^{\mathbf{b}}$ Department of Food Science,

9 SLU, Uppsala SE-750 07 Sweden, ${ }^{\mathbf{c} Q u a l i t y ~ G e n e t i c s ~ H B, ~ S E-242 ~} 92$ Hörby, Sweden,

10 d Department of Animal Nutrition and Management, SLU, Uppsala SE-750 07 Sweden,

$11{ }^{\mathrm{e}}$ Department of Clinical and Experimental Medicine, Linköping University, SE-581 85

12 Linköping, Sweden

13

14 Corresponding author: Assoc Prof Margareta Wallgren, Department of Clinical Sciences,

15 Division of Reproduction, Box 7054, SLU, SE-750 07 Uppsala, Sweden. Telephone: +46-

16 18672173, Fax: +46-18673545, e-mail: margareta.wallgren@kv.slu.se

17

18 Short title: Sustained testicular effects of early anti-GnRH vaccination in pigs

19

Keywords: Early vaccination against GnRH; Sexual maturity; Reproductive organs; Sperm

21 morphology; Male pig

22 
Gonadotropin-releasing hormone $(\mathrm{GnRH})$ vaccine $\left(\operatorname{Improvac}^{\circledR}\right)$ is effective at diminishing boar taint by interfering with testis function. Early pre-pubertal vaccination at 10 and 14 weeks-of-age could be desirable if sufficient and sustained effect could be achieved. Crossbred male pigs $(n=24)$ were randomly assigned to three groups each with 8 individuals: an unvaccinated control group, one group vaccinated with Improvac ${ }^{\circledR}$ early at ages 10 and 14 weeks, and a third group vaccinated with Improvac at the standard ages of 16 and 20 weeks. The average age at slaughter was 25 weeks. At slaughter, reductions in testes weight and bulbourethral gland length of vaccinated pigs compared with controls were observed $(\mathrm{P}<0.001)$, accompanied by lowerered testosterone concentrations in peripheral blood $(\mathrm{P}<0.001)$. The diameter of tubuli seminiferi was affected; being $18 \%$ smaller in standard and $38 \%$ smaller in early vaccinated males, compared with controls $(\mathrm{P}<0.01)$. Leydig cells in vaccinated pigs became pycnotic, and their number decreased in early vaccinated pigs. Spermatogenesis was disrupted, evidenced by spermatocyte loss among standard vaccinated pigs to severe spermatogenic arrest among early vaccinated pigs. This histological picture was reflected in the absence of epididymal spermatozoa in 5 of 8 early vaccinated pigs and a dramatic reduction in the remaining 3 early vaccinated pigs. Among standard vaccinated pigs, $5 \%$ of the spermatozoa were morphologically normal $(>70 \%$ in controls, $\mathrm{P}<0.01)$. Early vaccination caused a more severe disruption of testicular structure and function than standard vaccination, thus providing an alternative for immunocastration of male pigs. 


\section{Introduction}

Incidence of boar taint, an off-odour in meat from some male pigs, is indirectly related to testicular hormones and sexual maturity (Zamaratskaia and Squires, 2009). Therefore, surgical castration has for a long time been the standard method used to prevent taint in meat from male pigs, despite being a subject of controversy. Dunshea et al. (2001) showed that vaccination against gonadotropin-releasing hormone $(\mathrm{GnRH})$ using $\operatorname{Improvac}^{\circledR}$ on male pigs raised for slaughter was successful in eliminating boar taint. The mode of action of the vaccine is to provoke an immune response to endogenous GnRH by two subcutaneous injections (primer and booster) of a synthetic GnRH analogue conjugated to a carrier protein at least four weeks apart, with the second injection no later than four weeks prior to slaughter. As a consequence of vaccination, the hypothalamic-pituitary-gonadal axis is disrupted, follicle stimulating hormone (FSH) and luteinizing hormone ( $\mathrm{LH})$ are not released and thus testicular dysfunction occurs. This vaccine has been further investigated in several controlled studies (Hilbe et al., 2006; Jaros et al., 2005; Zamaratskaia et al., 2008a, b), in which it was found that vaccinated male pigs had reduced testicular weight and bulbourethral gland length, and reduced plasma levels of the testicular hormones testosterone and oestrone sulphate.

A recently published study investigated the efficacy of Improvac $^{\circledR}$ on sexual maturity, development of the reproductive organs, and the morphology of caudal epididymal spermatozoa in male pigs slaughtered at 4, 16 and 22 weeks after the second vaccine injection (Einarsson et al., 2009). None of the vaccinated male pigs was sexually mature at slaughter with the proportions of sexually mature unvaccinated males being $50 \%, 100 \%$ and $100 \%$ respectively. At all three slaughtering occasions, both testes weight and bulbourethral length were significantly reduced in the vaccinated pigs. Vaccination also clearly disrupted the 
number and morphology of the interstitial Leydig cells. Spermatogenesis was affected to various degrees in the vaccinated male pigs, from mild disruption to severe loss of germ cells. The results indicated a suppressing effect of vaccination on testicular maturity for at least 22 weeks after the second vaccine injection. It remains to be studied whether such a sustained effect might be obtained by early (pre- or early pubertal) use of Improvac ${ }^{\circledR}$. The rationale for such study would be that the testis would be more dramatically and perhaps irreversibly affected by an earlier vaccination against GnRH simply because it would hamper, among other actions, testosterone stimulation of spermatogenesis. Leydig cells are not only responsible for the production and storage of testosterone, but they also produce other hormones and factors relevant for spermatogenesis and testicular function (Raeside et al., 2006; Ge et al., 2008). Affected Leydig cells would result in a lack of available testosterone in the testis and such an early depletion of testosterone levels in the testicular fluid would strongly affect the ability of the epididymal epithelium to mature the spermatozoa.

To the best of our knowledge, no study has yet investigated whether the above presumed effects on the reproductive organs and sperm morphology of male pigs can be elicited by an early (pre-pubertal or early pubertal) vaccination with Improvac ${ }^{\circledR}$. The present experiment was therefore designed to investigate the efficacy of early vaccination of male pigs with Improvac $^{\circledR}$ at 10 and 14 weeks of age (pre-pubertal or early pubertal) on the development of reproductive organs and the morphology of cauda epididymal spermatozoa, examined post mortem at 25 weeks of age.

4

5

\section{Material and methods}

\subsection{Animals}


A total of 24 crossbred non-castrated male pigs (Swedish Yorkshire dams $\times$ Swedish Landrace sires) were included in this study. The five sires used were randomly selected among available Landrace sires. The study was performed at Funbo-Lövsta Research Station,

101 SLU, Sweden.

\subsection{Experimental design}

104 Pigs within litter were randomly assigned to three groups. The controls (group i) were kept 105 intact throughout the study. No placebo substance was administered. Pigs in two treatment 106 groups were each given two doses of Improvac ${ }^{\circledR}$ (Pfizer Inc Animal Health, Stockholm,

107 Sweden, $2 \mathrm{~mL}$ per dose). Pigs in the early vaccination group (group ii), were given their first 108 injection at age 10 weeks (69.0 \pm 7.8 days; mean \pm SD; live weight (LW) $28.0 \pm 8.6 \mathrm{~kg})$ and 109 the second injection at an age of 14 weeks $(97.0 \pm 7.8$ days; LW $44.2 \pm 10.8 \mathrm{~kg})$. Pigs in the 110 standard vaccination group (group iii) were vaccinated according to the manufacturer's 111 recommendation: the first injection was given at age 16 weeks $(112.0 \pm 6.8$ days; LW $60.6 \pm$ $1129.6 \mathrm{~kg})$ and the second injection at age 20 weeks (140.0 \pm 6.8 days; LW $85.4 \pm 10.6 \mathrm{~kg})$. Pigs 113 were raised in pens of eight. All pigs were fed the same commercial diet (12.4 MJ ME per kg, 114 digestible CP 13.5\%) twice a day according to the standard feeding regimen for 115 growing/finishing pigs in Sweden (Andersson et al., 1997). Pigs were weighed individually at 116 the start of the study then fortnightly until their final weighing one day prior to slaughter.

117 Slaughter was performed on two occasions per pen at a live weight of approximately $115 \mathrm{~kg}$ 118 (i.e. normal slaughter weight in Sweden; $117.2 \pm 9.4 \mathrm{~kg} ; 177.8 \pm 5.7$ days).

120 The study was approved in advance by the local Ethics Committee on Animal Research, 121 Uppsala, Sweden ensuring compliance with EC Directive 86/609/EEC for animal 122 experiments. 
125 Blood samples were taken by jugular venipuncture using vacutainer tubes from all pigs one

126 day prior to slaughter. Blood plasma was harvested and stored at $-80{ }^{\circ} \mathrm{C}$ until analysed. Total

127 testosterone concentration was measured with radioimmunoassay procedures (Diagnostic

128 Products, Los Angeles, CA, USA) in 50- $\mu$ l plasma aliquots, according to manufacturer's

129 instructions. The manufacturer reported a sensitivity of this assay of $0.04 \mathrm{ng} / \mathrm{mL}$ with an intra-

130 assay $\mathrm{CV}$ of $4.0-18.0 \%$ and an inter-assay $\mathrm{CV}$ of $5.9-12.0 \%$, depending on the testosterone

131 concentrations.

\subsection{Examination post mortem.}

134 Testes with epididymides and accessory sexual glands were removed at slaughter.

135 Reproductive organs were measured at the slaughterhouse. Testicular weight, as paired testes,

136 was recorded and the length of both bulbourethral glands was measured to determine the

137 average length of each pair of bulbourethral glands. Samples from the proximal and distal

138 testes, were fixed in a $2.5 \%$ solution of glutaraldehyde in cacodylate buffer $(\mathrm{pH} 7.2,500$

$139 \mathrm{mOsm})$, paraffin-embedded and conventionally sectioned and stained with haematoxylin and

140 eosin for histology. The tubular diameter in each specimen was measured manually using an

141 ocular micrometer when examining the slides at $100 \times$ magnification. For examination of

142 sperm morphology, cauda epididymal content (cauda spermatozoa) was retrieved at the

143 slaughterhouse, and transferred to buffered formol saline (Hancock, 1957). At the semen

144 laboratory, sperm morphology was evaluated by experienced laboratory assistants in wet

145 formol saline-fixed preparations (Bane, 1961) and in air-dried smears stained with

146 carbolfuchsin-eosin according to the method described by Williams (1920) and modified by

147 Lagerlöf (1934). In the wet smears, 200 spermatozoa, when possible, were checked under a 
148 phase contrast microscope (1000× magnification). All abnormalities on any given

149 spermatozoon were counted and the overall frequencies were classified according to Bane

150 (1961). For a more detailed examination of the sperm head, when possible, 500 spermatozoa

151 were checked in each stained smear under a light microscope at a magnification of 1000x.

152 Sperm head morphology was classified according to Lagerlöf (1934). The morphological

153 abnormalities were expressed as a percentage of the total number of counted spermatozoa.

154

$155 \quad 2.5$ Statistical analysis

156 Statistical analyses were performed using the procedure GLM in SAS (SAS Institute, Cary,

157 N.C., USA, version 9.1). The model included the fixed effect of treatment (control, early

158 vaccination or standard vaccination). The level of testosterone in plasma was log-transformed

159 to normalize the distribution. Statistical significance was set to $\mathrm{P}<0.05$.

160

\section{Results}

162

163

\subsection{Reproductive organs}

164 The effect of early and standard vaccination on testes weight and bulbourethral gland length

165 at slaughter is presented in Table 1. Both testes weight and bulbourethral gland length were

166 reduced $(\mathrm{P}<0.001)$ after the second vaccine injection compared with the entire male pigs

167 (controls). Testicular size of standard and early vaccinated pigs decreased with 58\% and 80\%,

168 respectively $(\mathrm{P}<0.001$ for both), compared with controls. Corresponding reductions for

169 bulbourethral lengths were $37 \%$ and $48 \%$, respectively ( $\mathrm{P}<0.001$ for both). In early vaccinated

170 pigs, testes weight and bulbourethral gland length decreased with $53 \%(\mathrm{P}=0.019)$ and $18 \%$

$171(\mathrm{P}=0.017)$ compared with standard vaccinated pigs. 
1733.2 Concentrations of testosterone in peripheral blood at slaughter

174 Testosterone concentrations, measured in peripheral blood plasma on the day prior to

175 slaughter, were lower in vaccinated pigs $(0.04$ and $0.05 \mathrm{ng} / \mathrm{mL})$ compared to controls $(1.4$ $176 \mathrm{ng} / \mathrm{mL} ; \mathrm{P}<0.001$ ) (Table 1). There was no significant difference in plasma testosterone 177 concentration between early and standard vaccinated pigs.

178

\subsection{Testicular histology}

180 Individual variation in testicular histology was present between control pigs, but their

181 testicular tissue showed mostly normal appearance in relation to presence, size and 182 distribution of typical eosinophilic Leydig cells (lc in Figure $1 a^{\prime}$ and $1 a^{\prime \prime}$ ) as well as 183 seminiferous tubuli. Spermatogenesis was fully developed in all controls at age 25 weeks

184 although some variation in size and degree of intact spermatogenesis was observed. That 185 variation was, however, to be expected for the age of pigs.

186 In vaccinated male pigs, testicular histology was clearly affected. Compared with controls, 187 tubular diameter was reduced by a mean of $18 \%$ in the standard vaccinated pigs and more 188 than $38 \%$ in the early vaccinated pigs $(\mathrm{P}<0.01)$. Together with an apparent reduction in the 189 size of the interstitium (compare Figures 1a to 1c), such morphological differences are 190 reflected in the significant diminution of testicular weight (Table 1). Vaccination with

191 Improvac $^{\circledR}$ clearly disrupted the number and morphology of the interstitial Leydig cells in the 192 standard vaccinated pigs and dramatically so in the early vaccinated animals (Fig. 1a-c"). The

193 Leydig cells lost their cytoplasmic eosinophilia, were fewer, and were represented by 194 pycnotic-like nuclei, difficult to distinguish from the interstitial fibroblasts and endothelial 195 cells. Spermatogenesis was also clearly affected in vaccinated pigs. In standard vaccinated 
196 pigs (Fig.1b-b”), changes ranged from mild disruption such as spermatocyte loss and

197 decrease in the normal number of layers of germ cells to severe loss of germ cells including 198 tubuli being Sertoli cell-only i.e. complete disappearance of germ cells. In early vaccinated

199 pigs, however, the changes were more dramatic with only 3 out of 8 specimens presenting 200 tubuli with spermatocytes or round spermatids. Most specimens had shrunken tubuli with 201 only Sertoli cells or a few spermatocytes (Fig.1c-c').

The morphology of spermatozoa collected from the cauda epididymides is summarised in

Table 2. The sperm morphology of controls was within normal limits for their age. Among early vaccinated pigs, there were no spermatozoa collectable in 5 out of 8 animals. In the remaining 3 males, the number of spermatozoa collected was extremely reduced: less than 100 were counted, after centrifugation of the fixed suspension. The most striking difference between controls and vaccinated pigs was the proportion of spermatozoa with normal morphology: only about 5\% of spermatozoa in the vaccinated pigs were normal compared 211 with more than $70 \%$ in the controls $(\mathrm{P}<0.01)$. Among the deviant spermatozoa, the dominant 212 morphological abnormality was the proportion of immature spermatozoa carrying proximal cytoplasmic droplets $(\mathrm{P}<0.001)$. Likewise, the proportions of spermatozoa depicting pathological sperm heads, or midpiece defects were higher $(\mathrm{P}<0.05)$ in vaccinated pigs compared with controls. Differences were not seen between early and standard vaccinated 216 pigs, but the number of early vaccinated pigs with enough spermatozoa for evaluation was too 217 small to accurately compare these differences.

\section{Discussion}


221 In accordance with earlier studies (Zamaratskaia et al., 2008b; Einarsson et al., 2009), 222 standard vaccination with Improvac $^{\circledR}$ significantly reduced both testes weight and 223 bulbourethral gland length alongside with a change in the hormonal profile of male pigs at 224 slaughter, (Zamaratskaia et al., 2008b). As far as we are aware, this is the first study 225 investigating reproductive tissues of male pigs vaccinated as early as at 10 and 14 226 weeks-of-age, before puberty or in early puberty. Considering that the response to Improvac ${ }^{\circledR}$ 227 vaccination is believed to be temporary and that after some time the animal is expected to 228 attain normal testicular function it is somewhat surprising to find both testes weight and 229 bulbourethral gland length reduced in early vaccinated pigs compared with standard 230 vaccinated pigs. The time between second vaccination and attainment of normal testicular 231 function is, however, not yet determined although there are indications that the effects of 232 Improvac $^{\circledR}$ on puberty-related factors last for at least 22 weeks (Zamaratskaia et al., 2008b). 233 In the present study, none of the animals recovered from the effects of Improvac ${ }^{\circledR}$, indicating 234 long-lasting effects of the suppression of $\mathrm{GnRH}$ on the hypothalamic-pituitary-gonadal axis 235 when vaccinating at 10 and 14 weeks of age. The drastic reduction in testosterone 236 concentrations in peripheral blood in vaccinated pigs suggests a hypo-function of the Leydig 237 cells and presumably a lack of GnRH production, effects that oppose those observed when 238 GnRH had been chronically administered in pre-pubertal male pigs (Dijkstra et al., 1988).

240 The histological status of the testes of vaccinated pigs was dramatically affected, with major 241 disruption of spermatogenesis, and a clear effect on the number and size of the Leydig cells 242 (Hilbe et al., 2006; Einarsson et al., 2009). These effects were even more conspicuous among early vaccinated pigs which had testes only $20 \%$ of the weight of the control pigs. The clear 244 relationship between the disruption of Leydig cell morphology and the low levels of 
testosterone in circulating plasma provides further evidence of the sustained effects of the

246 vaccination, particularly early vaccination.

248 The morphology of the cauda epididymal spermatozoa indicated sexual maturity for several 249 of the control male pigs but none for the vaccinated male pigs. Among the vaccinated pigs, 250 the dominant morphological abnormalities were the proportion of immature spermatozoa and 251 abnormal sperm heads. Similar results were reported by Einarsson et al. (2009). No 252 differences in sperm morphology were found between early and standard vaccinated pigs. However, 5 of 8 early vaccinated pigs had no spermatozoa in the cauda epididymis and, of the remaining 3 , less than 100 spermatozoa could be seen.

The overall picture indicates that early vaccination have caused an irreversible disruption of the testicular structure and function. Spermatogenesis and Sertoli cell function (Raeside et al., 1999; Ge et al., 2008; Roser, 2008) depend on testosterone diffusing through the tubuli walls and into the testicular fluid that flows through the epididymis (Raeside et al., 2006; Sofitikis et al., 2008). A lack of testosterone during the maturational period thus have permanently 261 affected spermatogenesis, either through a direct effect on germ cells, causing their apoptosis, 262 or indirectly by affecting Sertoli cell function (Huhtaniemi \& Toppari, 1995; Roser, 2008; 263 Sofitikis et al., 2008). The evident numbers of Sertoli cell-only tubuli would suggest that these 264 testes could not return to normality since most germs cells (including spermatogoniae) had 265 been destroyed. A high proportion of abnormalities in the few spermatozoa that reached the 266 epididymal cauda was also evident, the lower concentration of testosterone could not maintain 267 the function of the epithelial target cells or their capacity to convert testosterone to the 268 functional androgen dihydrotestosterone (Gloyna and Wilson, 1969; Aafjes and Vreeburg, 
1972; Setty, 1979). Regardless, the result is the same: a diminished epididymal function and an impairment of sperm maturation (Setty 1979).

272 Taken together, our results indicate that early vaccination causes a disruption of testicular 273 structure and function to pigs at least until slaughter age ( 25 weeks). Long-term recovery of 274 vaccinated male pigs from the effects of Improvac ${ }^{\circledR}$ is yet to be studied.

\section{Conclusions}

The results presented in this study show that both early and standard vaccination against 280 GnRH with Improvac ${ }^{\circledR}$ clearly suppressed reproductive function in male pigs. The crucial reduction in circulating testosterone, and the concomitant reduction in size of testes and bulbourethral glands, as well as the effects on spermatogenesis and the number and size of the Leydig cells was even more pronounced among the early vaccinated male pigs than among 284 the standard vaccinated male pigs. This indicates that vaccination at ages of 10 and 14 weeks 285 causes a disruption of testicular structure and function to pigs at least until the age of 25 weeks. This puts in question the reversibility of the effects of vaccination at a pre- or early 287 pubertal stage.

\section{Acknowledgements}

This study was supported by the Swedish Board of Agriculture. Pfizer is gratefully

292 acknowledged for providing $\operatorname{Improvac}^{\circledR}$ and additional financial support. The authors thank

293 Mr Michael Pearce for valuable comments on the manuscript. We also thank the staff at 
294 Funbo-Lövsta Research Station for taking excellent care of the pigs and for collecting data.

295 The authors are also grateful to Karin Selin-Wretling and Annika Rikberg for excellent 296 technical assistance with sperm morphology and histology.

\section{References}

Aafjes, J.H., Vreeburg, J.T., 1972. Distribution of 5-dihydrotestosterone in the epididymis of bull and boar, and its concentration in rat epididymis after ligation of efferent testicular ducts, castration and unilateral gonadectomy. J. Endocrinol. 53, 85-93.

Andersson, K., Schaub, A., Andersson, K., Lundström, K., Thomke, S., Hansson, I., 1997. The effects of feeding system, lysine level and gilt contact on performance, skatole

Bane, A., 1961. Acrosomal abnormality associated with sterility in boar. Proc. IVth Int. Congr.Anim. Reprod., The Hague, vol. 4, 810-817.

Dijkstra, G., van Vlissingen, J.M., Wensing, C.J., van Dorst-Bruijns, P.M., Degenhart, H.J., Erkens, J.H., van de Wiel, D.F., 1988. Chronic GnRH administration in prepubertal male pigs. A model to evaluate the effects of GnRH treatment in cryptorchydism.

312 Dunshea, F.R., Colantoni, C., Howard, K., McCauley, I., Jackson, P., Long, K.A., Lopaticki, boars with a GnRH vaccine (Improvac) eliminates boar taint and increases growth performance. J. Anim. Sci. 79, 2524-2535. 
Short- and long-term effects of immunization against gonadotropin-releasing hormone, using Improvac ${ }^{\mathrm{TM}}$, on sexual maturity, reproductive organs and sperm morphology in male pigs. Theriogenology $71,302-310$.

Ge, R., Chen, G., Hardy, M.P., 2008. The role of the Leydig cell in spermatogenic function. Adv. Exp. Med. Biol. 636, 255-269.

Gloyna, R.E., Wilson, J.D., 1969. A comparative study of the conversion of testosterone to 17-beta-hydroxy-5-alpha-androstan-3-one (Dyhydrotestosterone) by prostate and epididymis. J. Clin. Endocrinol. Metab. 29, 970-977.

Hancock, J.L., 1957. The morphology of boar spermatozoa. J. Roy. Micr. Soc. 76, 84-97.

Hilbe, M., Jaros, P., Ehrensperger, F., Zlinszky, K., Janett, F., Hässig, M., Thun, R., 2006.

Raeside, J.I., Christie, H.L., Renaud, R.L., 1999. Androgen and estrogen metabolism in the reproductive tract and accessory sex glands of the domestic boar (Sus scrofa). Biol. Reprod. 61, 1242-1248. 
Raeside, J.L., Christie, H.L., Renaud, R.L., Sinclair, P.A., 2006. The boar testis: the most versatile steroid producing organ known. In: Control of Pig Reproduction VII, Ashworth CJ \& RR Kraeling (eds), Nottingham Univ. Press, Manor Farm, Thrumpton, UK, 85-97 (Soc Reprod Fert Suppl 62).

Roser, J.F., 2008. Regulation of testicular function in the stallion: an intricate network of endocrine, paracrine and autocrine systems. Anim. Reprod. Sci. 107, 179-196.

Setty, B.S., 1979. Regulation of epididymal function and sperm maturation- endocrine approach to fertility control in male. Endokrinologie 74, 100-117.

Sofitikis, N., Giotitsas, N., Tsounapi, P., Baltogiannis, D., Giannakis, D., Pardalidis, N., 2008. Hormonal regulation of spermatognesis and spermiogenesis. J. Steroid. Biochem. Mol. Biol. 209, 323-330.

Williams W.W., 1920. Technique of collecting semen for laboratory examination with a review of several diseased bulls. Cornell Vet. 10, 87-94.

Zamaratskaia G., Andersson H.K., Chen G., Andersson K., Madej A., Lundström, K, 2008a. Effect of gonadotropin-releasing hormone vaccine (Improvac ${ }^{\mathrm{TM}}$ ) on steroid hormones, boar taint compounds and performance in entire male pigs. Reprod. Dom. Anim. 43, 351-359.

Zamaratskaia G., Rydhmer, L., Andersson, K., Chen G., Andersson K., Lowagie, S., Madej A., Lundström, K, 2008b. Long-term effect of vaccination against gonadotropinreleasing hormone, using Improvac ${ }^{\mathrm{TM}}$, on hormonal profile and behaviour of male pigs. Anim. Reprod. Sci. 108, 37-48.

Zamaratskaia, G., Squires E.J., 2009. Biochemical, nutritional and genetic effects on boar taint in entire male pigs. Animal 3, 1508-1521. 
367 Table 1. Effect of vaccination against GnRH on testis weight, bulbourethral gland length and testosterone concentrations in peripheral blood plasma at slaughter after standard and early vaccination with Improvac®. Entire male pigs Standard immunized male pigs Early immunized male pigs P-value

371 Paired testis weight $(\mathrm{g}) 553 \mathrm{a} \pm 34.5(\mathrm{n}=8) 232 \mathrm{~b} \pm 34.5(\mathrm{n}=8) 109 \mathrm{c} \pm 34.5(\mathrm{n}=8) 0.001$

372 Bulbourethral glands $(\mathrm{cm}) 12.6 \mathrm{a} \pm 0.40(\mathrm{n}=7) 8.0 \mathrm{~b} \pm 0.40(\mathrm{n}=7) 6.6 \mathrm{c} \pm 0.38(\mathrm{n}=8) 0.001$

373 Testosterone* $(\mathrm{ng} / \mathrm{mL}) 1.4 \mathrm{a}(0.69-2.90)(\mathrm{n}=7) 0.04 \mathrm{~b}(0.02-0.08)(\mathrm{n}=7) 0.05 \mathrm{~b}(0.03-0.11)$

$$
(\mathrm{n}=8) 0.001
$$

375 Full-size table

376 Least-square means \pm standard error of the mean. Least squares means with different superscript within row differ $\mathrm{P}<0.05$.

$378 *$ Least-square means and $95 \%$ confidence interval after back transformation to the original 379 scale. 
Table 2. Effect of immunization against $\mathrm{GnRH}$ on percentages of sperm abnormalities and proportions of normal spermatozoa collected from the cauda epididymides at slaughter after standard vaccination and early vaccination with Improvac ${ }^{\circledR}$.

\begin{tabular}{|l|l|l|l|l|}
\hline & $\begin{array}{l}\text { Entire male } \\
\text { pigs }\end{array}$ & $\begin{array}{l}\text { Standard immunized } \\
\text { male pigs }\end{array}$ & $\begin{array}{l}\text { Early immunized } \\
\text { male pigs }\end{array}$ & $\begin{array}{l}\boldsymbol{P} \text { - } \\
\text { value }\end{array}$ \\
\hline $\begin{array}{l}\text { Number of } \\
\text { animals }\end{array}$ & 8 & 8 & $3^{*}$ & \\
\hline
\end{tabular}

Sperm morphology (\%)

\begin{tabular}{|c|c|c|c|c|}
\hline $\begin{array}{l}\text { Abnormal head } \\
\text { shapes }\end{array}$ & $11.8^{\mathrm{a}} \pm 3.39$ & $22.6^{b} \pm 4.18$ & $26.6^{b} \pm 6.59$ & $<0.05$ \\
\hline Loose heads & $3.7^{\mathrm{a}} \pm 0.93$ & $3.2^{\mathrm{a}} \pm 1.34$ & $1.7^{b} \pm 0.48$ & $<0.05$ \\
\hline $\begin{array}{l}\text { Acrosome spec } \\
\text { defect }\end{array}$ & $3.7^{\mathrm{a}} \pm 0.97$ & $2.4^{a} \pm 0.65$ & $1.2^{\mathrm{b}} \pm 0.94$ & $n \mathrm{~ns}^{*}$ \\
\hline $\begin{array}{l}\text { Acrosome } \\
\text { abnormality }\end{array}$ & $2.3^{a} \pm 0.54$ & $2.6^{a} \pm 0.66$ & $1.7^{\mathrm{a}} \pm 0.53$ & $\mathrm{~ns}^{* *}$ \\
\hline Proximal droplets & $10.1^{a} \pm 4.21$ & $78.1^{b} \pm 6.27$ & $60.0^{b} \pm 19.30$ & $<0.001$ \\
\hline Distal droplets & $72.0^{a} \pm 5.74$ & $2.9^{b} \pm 1.59$ & $5.9^{b} \pm 2.67$ & $<0.001$ \\
\hline Midpiece defects & $1.3^{\mathrm{a}} \pm 0.24$ & $5.9^{\mathrm{a}, \mathrm{b}} \pm 2.95$ & $6.1^{b} \pm 1.61$ & $<0.05$ \\
\hline Simple bent tail & $2.5^{\mathrm{a}} \pm 0.61$ & $2.8^{\mathrm{a}} \pm 1.68$ & $4.2^{\mathrm{a}} \pm 1.87$ & $n s^{* *}$ \\
\hline $\begin{array}{l}\text { Normal } \\
\text { spermatozoa }\end{array}$ & $\begin{array}{l}71.1^{\mathrm{a}} \pm 6.27 \\
(39-95)\end{array}$ & $5.0^{\mathrm{b}} \pm 1.67(1-17)$ & $5.3^{\mathrm{b}} \pm 3.02(3-13)$ & $<0.01$ \\
\hline
\end{tabular}

Least-square means \pm standard error of the mean. Least squares means with different superscript within row

388 differ at $P<0.05$.

389 "In early vaccinated entire male pigs no spermatozoa were found in the cauda epididymides of 5 out of 8 males 390 pigs, while in the remaining 3 male pigs ${ }^{1}$ the percentages of abnormalities are based on $<100$ spermatozoa. 391 "Non significant. 


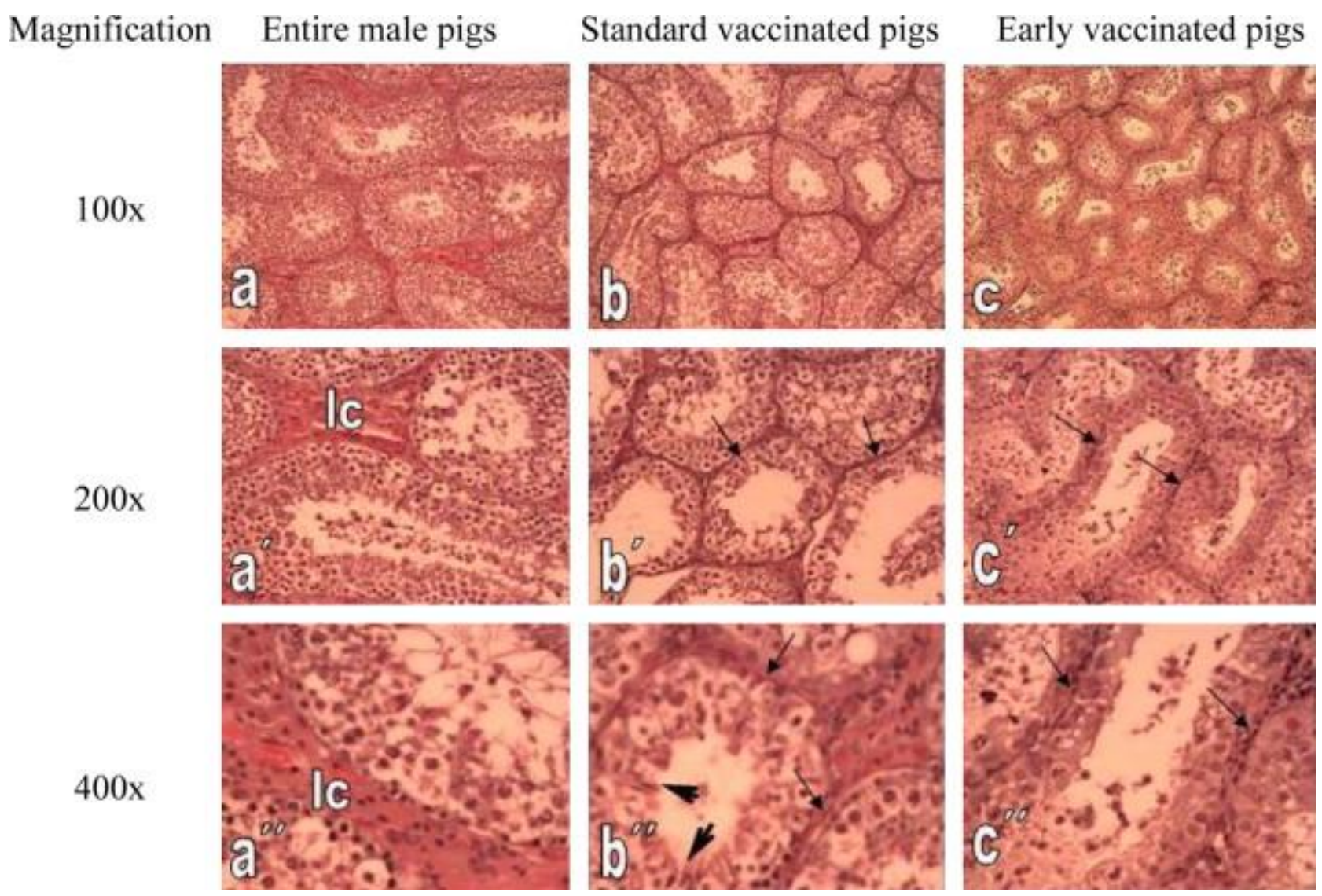

395 Fig. 1.

$396\left(\mathrm{a}-\mathrm{c}^{\prime \prime}\right)$ Light microphotographs of testicular tissue from entire male (group i, left column

397 figures a and $\mathrm{a}^{\prime \prime}$ ), Improvac ${ }^{\circledR}$ - standard vaccinated (group ii, middle column, figures

$398 \quad \mathrm{~b}$ and $\mathrm{b}^{\prime \prime}$ ) and $\operatorname{Improvac}^{\circledR}$ - early vaccinated (group iii, right column, figures $\mathrm{c}$ and $\mathrm{c}^{\prime \prime}$ )

399 pigs slaughtered at 25 weeks of age. Note the diminution in the size of the

400 seminiferous tubules $(\mathrm{a}-\mathrm{c})$, and in the space of the interstitial tissue (arrows)

401 containing the Leydig cells (lc) in the vaccinated pigs $\left(a^{\prime}-c^{\prime}\right)$, and the number of

402 layers in the epithelium $\left(\mathrm{a}^{\prime \prime}-\mathrm{c}^{\prime \prime}\right)$, for vaccinated pigs compared to controls. While

403 some standard vaccinated pigs still had tubuli with elongated spermatids ( $\mathrm{b}^{\prime \prime}$ arrow

404 heads), most tubuli in early vaccinated pigs only had Sertoli cells or spermatocytes

405 left $\left(c^{\prime \prime}\right) .(a-c) 100 \times,\left(a^{\prime}-c^{\prime}\right) 200 \times$, and $\left(a^{\prime \prime}-c^{\prime \prime}\right) 400 \times$ magnification. 